\title{
A!
}

This is an electronic reprint of the original article.

This reprint may differ from the original in pagination and typographic detail.

Dolejsova, Marketa

\section{Edible Speculations}

Published in:

Global Discourse

DOI:

$10.1332 / 204378920 X 16069559218265$

Published: 18/01/2021

Document Version

Peer reviewed version

Please cite the original version:

Dolejsova, M. (2021). Edible Speculations: Designing Everyday Oracles for Food Futures. Global Discourse, 11(1-2), 161-180. https://doi.org/10.1332/204378920X16069559218265

This material is protected by copyright and other intellectual property rights, and duplication or sale of all or part of any of the repository collections is not permitted, except that material may be duplicated by you for your research use or educational purposes in electronic or print form. You must obtain permission for any other use. Electronic or print copies may not be offered, whether for sale or otherwise to anyone who is not an authorised user. 


\section{Global Discourse}

\section{Edible Speculations: Designing Everyday Oracles for Food Futures}

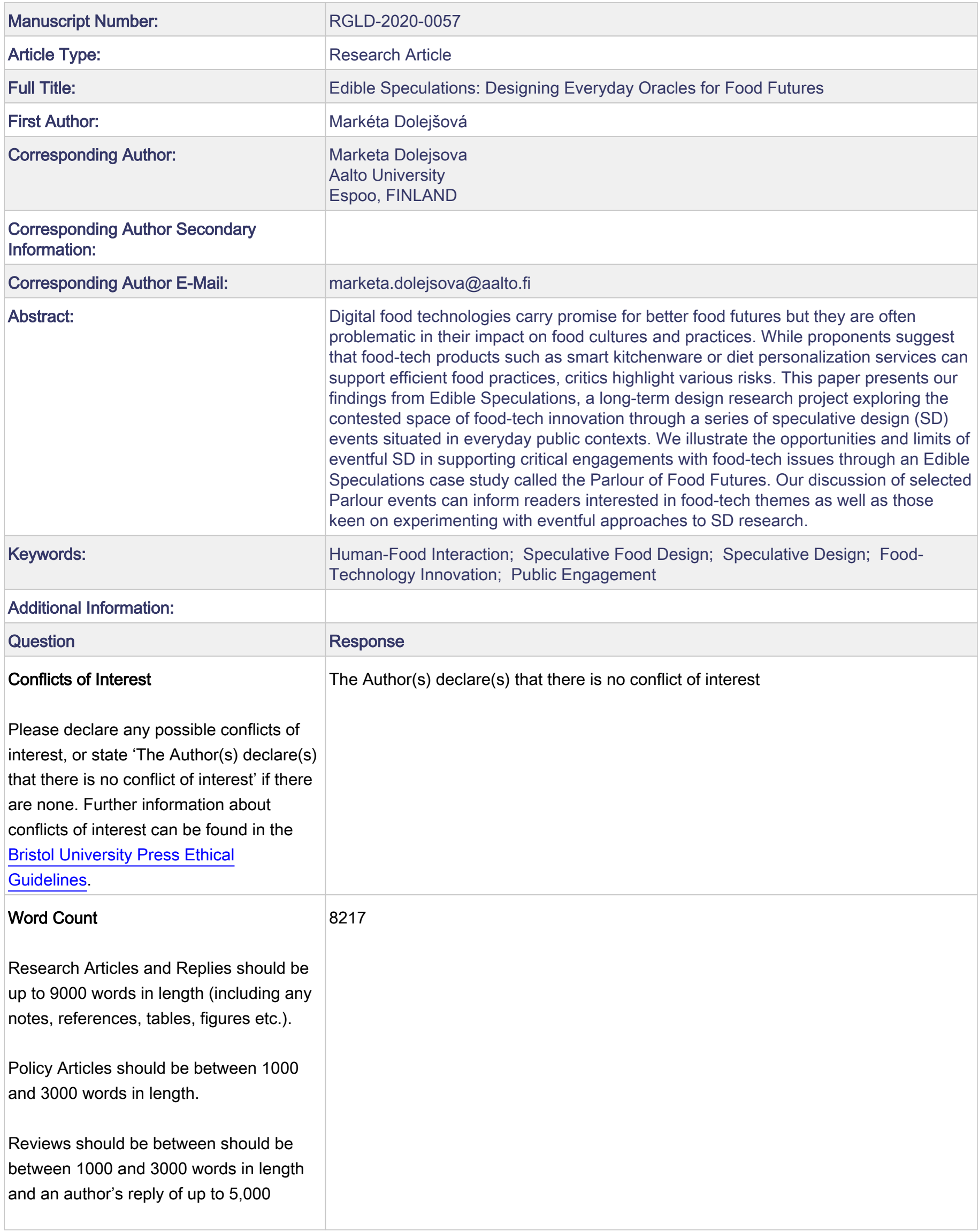


words. Review articles, on several monographs, should be up to 5000 words.

Themed issue title

Please state which themed issue this submission is for.

\section{Provide a tweet}

Please provide a tweet for Global

Discourse to send out about your article, so that we can help promote your work as widely as possible. The tweet should summarise the key findings of your article in laymen's terms, and no longer than 130 characters.

Funding Information:

\begin{tabular}{|l|}
\hline \\
\hline
\end{tabular}

Corresponding Author's Institution:
Staying with Speculation

In 'Edible Speculations' @ma_terie presents \#speculative design inquiry into \#foodtech innovation issues, using Tarot as a medium

European Regional Development Fund (CZ.02.1.01/0.0/0.0/16_019/0000734)

Horizon 2020

(870759)

Aalto University 


\title{
Edible Speculations: Designing Everyday Oracles for Food Futures
}

\author{
Markéta Dolejšová ${ }^{1}$ \\ ${ }^{1}$ Charles University, Prague, Czech Republic; Aalto University, Espoo, Finland
}

This work has been supported by the European Regional Development Fund-Project "Creativity and Adaptability as Conditions of the Success of Europe in an Interrelated World" (No.

CZ.02.1.01/0.0/0.0/16_019/0000734) and by the "CreaTures (Creative Practices for Transformational Futures)" project, funded from the European Union's Horizon 2020 research and innovation programme under grant agreement No 870759.

\begin{abstract}
:
Digital food technologies carry promise for better food futures but they are often problematic in their impact on food cultures. While proponents suggest that food-tech products such as smart kitchenware or diet personalization services can support efficient food practices, critics highlight various risks. This paper presents our findings from Edible Speculations, a long-term design research project exploring the contested space of food-tech innovation through a series of speculative design (SD) events situated in everyday public contexts. We illustrate the opportunities and limits of eventful SD in supporting critical engagements with food-tech issues through an Edible Speculations case study called the Parlour of Food Futures. Our discussion of selected Parlour events can inform readers interested in food-tech themes as well as those keen on experimenting with eventful approaches to SD research.
\end{abstract}

\section{Key words:}

Human-Food Interaction, Speculative Food Design, Speculative Design, Food-Technology Innovation, Public Engagement

\section{Word count:}

7569 (without references), 8217 (with references) 


\title{
Edible Speculations: Designing Everyday Oracles for Food Futures
}

\begin{abstract}
Digital food technologies carry promise for better food futures but they are often problematic in their impact on food cultures. While proponents suggest that food-tech products such as smart kitchenware or diet personalization services can support efficient food practices, critics highlight various risks. This paper presents our findings from Edible Speculations, a long-term design research project exploring the contested space of food-tech innovation through a series of speculative design (SD) events situated in everyday public contexts. We illustrate the opportunities and limits of eventful SD in supporting critical engagements with food-tech issues through an Edible Speculations case study called the Parlour of Food Futures. Our discussion of selected Parlour events can inform readers interested in food-tech themes as well as those keen on experimenting with eventful approaches to SD research.
\end{abstract}

\section{INTRODUCTION}

Human food practices are an essential part of everyday life that can be a source of gustatory pleasures as well as good health. However, numerous public health and sustainability reports published in recent years make it clear that the ways in which we produce and consume food are harming the health of individuals as well as the Planet (e.g., Willet et al., 2019). Issues with malnutrition and environmental unsustainability in food systems motivate a growing sector of food-technology designers and entrepreneurs aiming to solve food problems through technological innovation (CBInsights, 2018). Digital technologies such as Al-based kitchenware, online diet personalization services, or various smart food apps carry a promise of better food futures but they also raise some concerns (Dolejšová et al., 2019; Lupton, 2017; Norton et al., 2017). What are the implications of food-technologies for social rituals and cultural traditions that typically emerge around food? How are these technologies changing the creative involvements we have with food as cooks and chefs? Is it safe to rely on recipes and diet recommendations provided by algorithms? What are the privacy implications of sharing personal data over online food services? How is food-tech innovation impacting the food job market?

The social impact of food-tech innovation is a relatively recent topic of interest for scholars. Food Studies, as the flagship in the area of food-related research, has shown only a peripheral interest in food-tech innovation issues (Lupton, 2017). A relevant discussion has been developing in Human-Food Interaction (HFI), an emerging field gathering food-oriented authors across disciplines that originated in Human-Computer Interaction (Altarriba Bertran et al., 2019). A recent literature review of $\mathrm{HFI}$ scholarship (ibid) shows that authors in the field have, to a large extent, embraced techno-centric perspectives oriented to the design of solutions. HFI projects that propose to fix, speed up, ease, or otherwise make interactions with food more efficient outweigh those reflecting on broader-and often challenging - social circumstances of embedding technology into everyday-life contexts. Critical works addressing not only the 

existing HFI literature.

This gap in $\mathrm{HFI}$, and the overall lack of critical scholarly reflection on the possible implications of food-tech innovation for food practices and cultures, motivates the Edible Speculations project. Initiated in 2011, the ongoing project involves a series of design research case studies examining food-tech issues through speculative design (SD) events situated in various public venues. SD and related approaches such as design fiction are recognised for enabling critical thinking rather than problem-solving (Blythe et al., 2016; Dunne \& Raby, 2013; Elsden et al., 2017). This is typically facilitated through design exhibitions and expert workshops where design and research professionals discuss contemporary socio-technical problems and collectively imagine what "our" futures might look like. These approaches to SD have been criticized for disseminating only to selected social groups, with critics asking: who is included in the generalised "we" of SD futuring and who is left behind; why and for whose benefit? (Martins, 2014; Tonkinwise, 2016). In line with this critique, Edible Speculations experiments with the format of co-creative SD events that are accessible to diverse publics. Using a variety of speculative food design artefacts, the project creates experimental spaces for interested stakeholders to come together and engage in critical as well as imaginative reflections on existing food-tech issues.

In this paper, we discuss one selected Edible Speculations case study, the Parlour of Food Futures, and a series of five Parlour events that were implemented at five public festivals between 2017-19. At the events, participants engaged in one-on-one Tarot readings performed over a bespoke deck of Food Tarot cards, and crafted food futures scenarios. Through empirical observations and analysis of what participants made and said, we explored the potential of eventful SD in supporting creative and reflective human-food-tech engagements. Our findings can inform HFI and other food-oriented scholars, as well as broadly any authors interested in eventful approaches to SD. Besides contributing to these design and research areas, Edible Speculations events enable experiences that are meaningful also for the participating public, as we unpack later in this text. Before discussing the Parlour study, we start with an overview of food-tech innovation and related issues, followed by a brief introduction to the larger Edible Speculations project and the eventful speculative food design approach that stands in its center.

\section{FOOD-TECH INNOVATION: SOLVING OR MAKING PROBLEMS?}

The use of online digital technology for food-related purposes is not new. Already in the mid1990s, consumers privileged with Internet access could search websites and chat forums for recipes and dietary advice. Since then, the variety of food technologies has increased dramatically, catering to a full spectrum of people's food needs and desires. Recently popular is the category of smart kitchenware, such as the Wi-fi enabled oven June designed to support convenient, remote-controlled cooking. The smart oven has a system of embedded sensors and cameras that can recognize what food is inside and automatically adjust the ideal cooking time and temperature. Users can provide additional commands via the Alexa voice assistant and receive notifications about the cooking progress via the June smartphone app. Other than that, they do not need to do much. Instead of getting their hands dirty, they can just sit back and relax 
and wait till their dinner gets done. While potentially convenient, this hands-free remotecontrolled cooking strips the user-cook, chef-of their active, or even creative, involvement in the food making process. With June, food practices become disembodied: human cooks are put on autopilot, while technology becomes the driver of culinary decisions and actions. Furthermore, as reported in the available user reviews, the algorithmic chef June does not always get it right and might serve meals that are undercooked and potentially unsafe to eat (Wilson, 2016).

A rather different approach to data-driven optimisation of mundane food practices is embraced within the recent trend of gene-based personalised nutrition. Companies like DNAFit provide diet personalization services based on a low-cost analysis of a user's genetic predisposition to process particular food and nutrients. By following diet plans tailored to their DNA, users are promised to become "masters of their health" (quoted from DNAFit website). Yet at the same time, by sharing their personal genetic information with such commercial services, users are at risk of privacy infringements. Their sensitive data could be misused by third parties, such as pharmaceutical companies or healthcare insurers (Solberg, 2018). Instead of empowering users in their relationship to their health as promised, these diet services limit the control that users have over their personal data and, hence, their lives.

The practice of tracking consumers' personal data stands in the centre of automated shopping systems and "unmanned" grocery stores like Amazon Go or Bodega/Stockwell, where there is almost no human staff. To enjoy the cashier-less shopping in the Amazon Go supermarkets, customers need to use the Amazon Go app that tracks any item they take from store shelves and place in a shopping bag. An appropriate sum for the purchased goods is then automatically deducted from their Amazon account, leaving the Amazon empire with a track record of customers personal purchases and preferences. Such data insights, retrieved from their physical visit to a brick-and-mortar store, are the extra price that Amazon Go customers have to pay for this Just Walk Out Shopping experience that is fast, efficient and stripped of any social interaction. While it might be efficient for some, the sterile convenience of unmanned grocery shopping is certainly not a good fit for all social and cultural contexts.

The removal of jovial chats and brief social encounters with their local grocers-for many people a common part of their shopping experience (note that this text was originally written and submitted in summer 2019, before the Covid-19 pandemic)—was famously criticized with regards to another automated shopping solution, the Bodega pantry. The 'smart' Al-based pantry containing essential food and drugstore products was designed with the intention to replace the traditional bodegas_-mom and pop stores popular around the USA (Morabito, 2018). Shortly after its launch, the high-tech pantry got hit with a harsh criticism spread around social media pointing out that Bodega diminishes social aspects of grocery shopping, jeopardizes jobs of traditional bodega grocers and supports gentrification (facing this criticism, the Bodega company changed its name to a somewhat less culturally offensive "Stockwell").

These brief examples illustrate various opportunities and risks of integrating technology into everyday food practices and show the ambivalent impact of food-tech innovation on food 
cultures. Food-tech services designed to simplify food practices and solve problems "through a click" typically offer a generic fix while ignoring the diverse social and cultural contexts where these practices are situated. As a result, many of these techno-solutions are limited in their functions, and not only fail to solve what they promised, but also create new problems on their own. Technologies can reduce socio-culturally and sensorially rich food experiences into utilitarian, standardized tasks performed by algorithms; erode the creative potential embedded in material food practices; compromise consumer privacy; and bring other challenges to the table. This is not to say that we should avoid any attempts to innovate food systems through technology, but that any of such attempts need to be mindful of social food contexts and carefully consider the diverse impacts that innovation may have on food cultures. HFI scholarship, a prime venue to discuss food-tech innovation, has shown only a minor interest in these issues and the ambivalent socio-economic role of technology innovation in food cultures remains largely unexplored (Altarriba Bertran et al., 2019). The Edible Speculations project enters this space and explores the opportunities and limits of food-tech innovation through the critical lens of speculative design.

\section{EDIBLE SPECULATIONS: APPROACH}

The Edible Speculations project started with our interest in exploring the diverse-existing as well as imagined-ways in which novel smart technologies impact our everyday lives. Turning our focus to food, an everyday-life practice carrying diverse social, cultural and emotional meanings and values, was a convenient way to follow this interest in a creative and tasteful way. The ongoing project has so far involved six case studies that address a distinct scope of food-tech themes. ${ }^{1}$ Before we proceed with our discussion of the Parlour of Food Futures case study, we outline the speculative design approach driving Edible Speculations.

\section{Speculative Design}

The use of speculative design (SD) in the Edible Speculations project supports our goal to explore, reflect on and problematize existing food-tech solutions. As an approach to design research and practice, SD is fundamentally anti-solutionist, building on the recognition that a search for technological solutions can close down problems. Instead of reifying pragmatic solutions, SD enables "problem setting", which entails the development of conditions for problems to be discussed and understood from multiple viewpoints (Schön, 1984). The problem setting process is commonly facilitated through design artefacts that are provocative, interrogative and "slightly strange"-falling out of the common logic of things and supporting imaginations of the "not-quite-yet" realities (Dunne \& Raby, 2013). Although SD supports future imaginaries, it does not intend to predict the future but rather to speculate on how things could be, in order to critique and discuss possibilities.

\footnotetext{
1 These are: the HotKarot \& OpenSauce (www.hotkarot.cz), the StreetSauce (www.streetsauce.cz), the Fermentation GutHub (http://foodguthub.github.io), the BYOP[oop] (www.pooperleaks.tumblr.com), the Extreme Biopolitical Bistro (www.extremebistro.tumblr.com) and, finally, the Parlour of Food Futures (https://foodtarot.tech), which we discuss here.
} 
While the use of speculation as a design research approach was proposed already in the late 90s (e.g., Gaver \& Dunne, 1999; Gaver, 2002), SD came into a wider recognition upon the publication of Anthony Dunne and Fionna Raby's Speculative Everything (2013). Dunne \& Raby's book outlined SD as an exhibitable practice to be presented in art and design galleries, in the form of finished, fine-art looking artefacts. While recognizing its merit in articulating SD to a broader design audience, the exhibitable approach outlined by Dunne \& Raby soon became a subject of critique. This critique-often articulated by SD practitioners themselves-points out that SD exhibitions are detached from everyday-life realities, and, instead of considering concerns of wider public, cater to privileged (intellectual and wealthy) social groups (e.g., Martins, 2014; Tonkinwise, 2016). Furthermore, the finished form of exhibitable SD artefacts provides a limited option for the audience to intervene with their own active inputs and interpretations (Disalvo, 2016). These critiques and debates concerned with the need to make SD socially accessible, responsible and responsive, led to an increased interest in eventful, participatory forms of SD.

These SD approaches have been articulated through diverse formats, including public codesign workshops (Baumann et al, 2017; Blythe et al., 2016), performative enactments (Elsden et al., 2017), labs in the wild (Wilde, Underwood \& Pohlner, 2014), and speculative interventions into everyday-life realms (DiSalvo, 2016). Authors in this area often draw on the methods and techniques from participatory and co-design (Baumann et al., 2017; Blythe et al., 2016; Wilde, Underwood \& Pohlner, 2014), design anthropology (DiSalvo, 2016) and performative arts (Elsden et al., 2017). Such speculations—-presented as events rather than installation artefacts-extend the possibilities of SD to support critical and creative public engagement. Using SD to support a "designerly version of public engagement", as the sociologist Mike Michael suggests, offers an alternative to the "orthodox" public engagement methods commonly used by social scientists (2012, p. 540). Edible Speculations leverages these SD capabilities to create experimental spaces for participants to engage in critical, imaginative reflections on foodtech issues. The long-term project has been developed and refined through our own speculative practice but it bears resemblance to and is loosely inspired by the eventful SD approaches listed above. Edible Speculations makes use of the performativity of design enactments; the everydayness of speculative interventions and labs in the wild; as well as the hands-on character of SD workshops.

\section{Speculative Food Design}

Design research projects that use SD methods and techniques are sporadic in the existing foodoriented scholarship, both in and beyond HFI (Altarriba Bertran et al., 2019; Dolejšová, 2018). The existing body of speculative food design works comprises mostly art gallery artefacts and installations that are presented as art/design showcases rather than research inquiries. Recent years have seen a variety of curated exhibitions addressing possible food futures through spectacular SD objects. Marije Vogelzang's Future Food House (2013) presented, among others, Martí Guixé's installation Tonic Death Diet fantasizing about a Matrix-like food future where people live in virtual realities and nurture their physical bodies through magic food pills. The Meat the Future exhibition (2013) curated by the Next Nature Network showcased a variety of speculative lab-grown meat products such as the diegetic Knitted Steak prototype made of 
cultured muscle tissue threads, or the Celebrity Cubes that are cultured from stem cells of popculture celebrities. More recently, exhibitions such as the Future Food and the Edible Futures (both 2019) presented a range of food futurist visions, such as the diegetic Human Hyena foodware enabling users to digest rotten food.

While undoubtedly thought-provoking, these speculative food design exhibitions showcase finished authorial artifacts that are available for mere spectatorship and enable only limited options for audiences to actively participate and reflect on the food issues at hand. These exhibitable food speculations can be subjected to the same critique as exhibitable SD in general: to borrow from Carl DiSalvo, they are at risk of serving as mere "reductively spectacular commentaries", leaving us "hungry for more critical engagement" (2012a, p. 116117). Incidentally, one of the first SD projects that sparked a wave of criticism against exhibitable SD was food-oriented: the Republic of Salivation (2011) by designers Burton Nitta offered a dystopian vision of future food scarcity, where citizens receive limited portions of foodstuff rationed accordingly to the emotional and physical demands of their jobs. While the Republic of Salivation aimed to spark a debate about food insecurity issues, it was met with criticism highlighting the overt spectacularity of the project, which presented a shocking vision of future food scarcity. This scarcity however, is a daily reality for many people already today (Thackara, 2014). The project was condemned for being a decontextualized, reductionist commentary on food cultures that is detached from the real-world problems that it speculates upon.

To our knowledge, there exists only a handful of speculative food design projects aiming to engage their audiences in a participatory manner, enabling them to contribute their personal food experiences and insights. Notable example in this niche field is the long-term work of the Center for Genomic Gastronomy (CGG), consisting of public workshops, experimental tastings, field trips and other participatory events addressing issues in food and biotechnological advancement. CGG's De-Extinction Deli (2013) is a fantastic food stall inviting visitors to discuss the speculative possibility of reviving, and possibly consuming, extinct species such as the woolly mammoth. Stall visitors are offered the opportunity to taste diegetic samples of extinct foods, engage in a public poll, and write pre-addressed postcards that can be mailed to leading researchers in the field of de-extinction. This speculative design in the form of a provocative food stall treated visitors as more than mere spectators and encouraged them to contribute their creative and reflective inputs.

Following on from our earlier discussion of SD, we propose that these participatory, eventful approaches to speculative food design carry a promising yet largely unexplored potential for public engagement. The Edible Speculations project leverages this potential and extends the niche space of eventful speculative food design through its series of six case studies. The case studies are organised as design research events that are situated in various everyday-life contexts to engage food experiences and reflections of diverse publics, mostly casual passersby. Considering that most people eat and make food, and as such are implicated in food system issues as well as in the shared food futures to come, gathering food insights from a 
diverse pool of individuals is not only practical and sensible but also ethical. In what follows, we discuss our findings from the Parlour of Food Futures case study.

\section{PARLOUR OF FOOD FUTURES: EDIBLE SPECULATIONS CASE STUDY}

\section{Background}

The Parlour of Food Futures is a speculative oracle that explores possible food-tech futures through the $15^{\text {th }}$ century game of Tarot. These explorations are performed over a bespoke Food Tarot card deck that presents 22 food-tech tribes imagining how food and eating practices might look in the near future (figure 1). Although primarily future-oriented, each tribe refers to some existing or emerging food-tech trend: for instance, Datavores refer to quantified diets, Turing Foodies to the use of Al in the kitchen, Genomic Fatalists to DNA-based diet personalisation. During the one-on-one readings performed in the Parlour, participants are prompted to discuss food-tech issues shown on their selected cards, share their food experiences and craft future food scenarios.

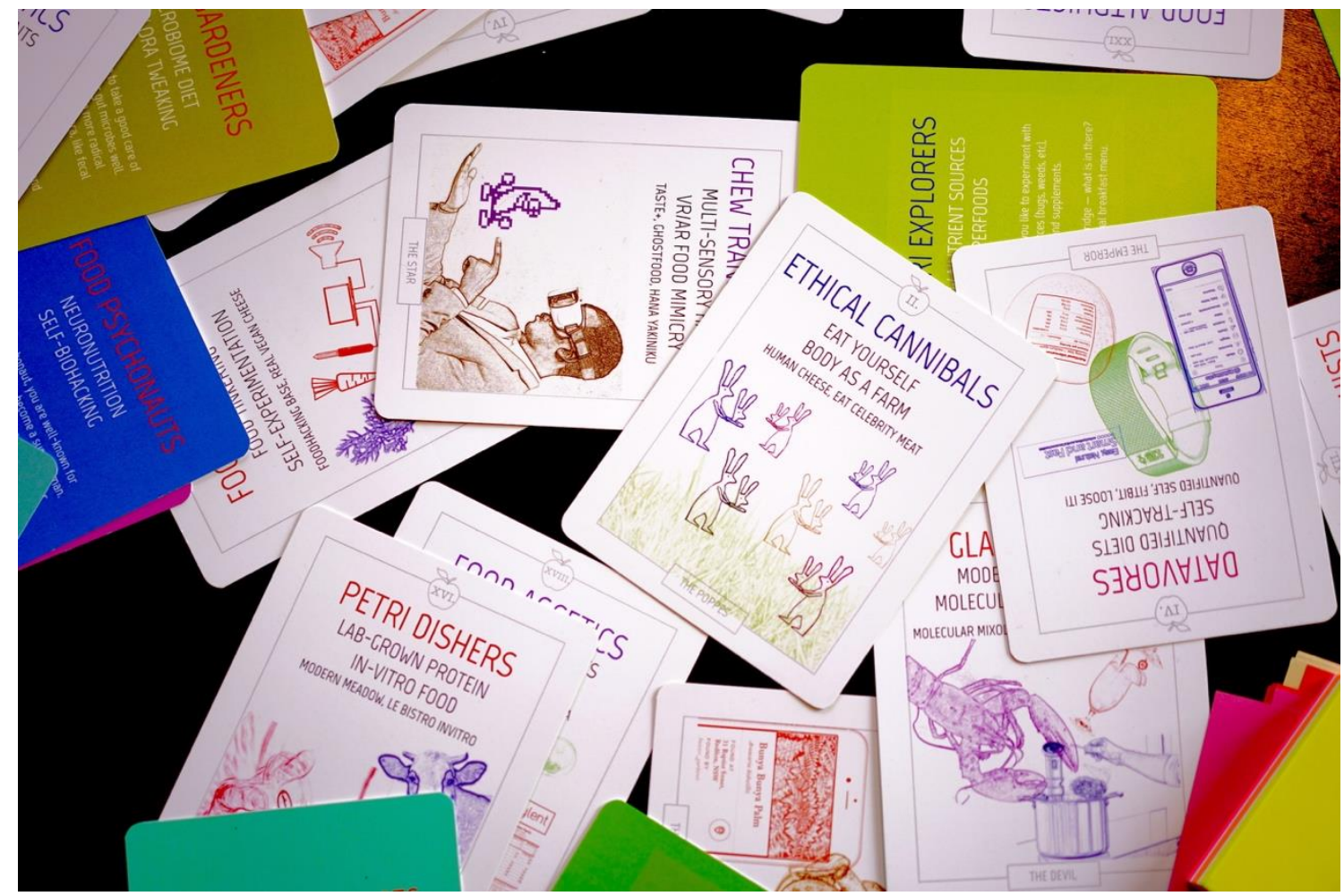

Figure 1: Food Tarot cards.

The Parlour project is inspired by the Tarot technique that has been traditionally used in card games as well as for divinatory purposes and future speculations. With Tarot, we aim to enable playful human-food interactions and support the notion of food futures as uncertain but also always connected to the past and reflecting how we engage with food in the present. The Food Tarot cards are inspired by the Tarot de Marseille deck (Major Arcana) that includes 22 cards 
with various philosophical and astronomical motives embodied by elements such as The Empress or The Magician. Each of these elements has a specific symbolic meaning, which we kept and translated into our Food Tarot version. For instance, the Tarot card of The Emperor that symbolises the urge to rule and control was matched with the card of Datavores-a tribe of Quantified Self dieters controlling their bodies through self-tracking of their metabolic processes (figure 2). The card of The Magician-signifying the potential for transformation-is matched with the diet tribe of Food Gadgeteers who experiment with 3D food printing to transform ordinary food items into more spectacular forms. The card of the Empress-representing the dominion over growing things - became a food-tech tribe of Gut Gardeners who experiment with DIY biohacking to grow their own food. To arrive at the 22 Food Tarot tribes, we conducted a literature review of existing and emerging food-tech trends (details in Dolejšová, 2018). Drawing on the review, we selected 22 trends and matched those with the original Marseille symbolics.
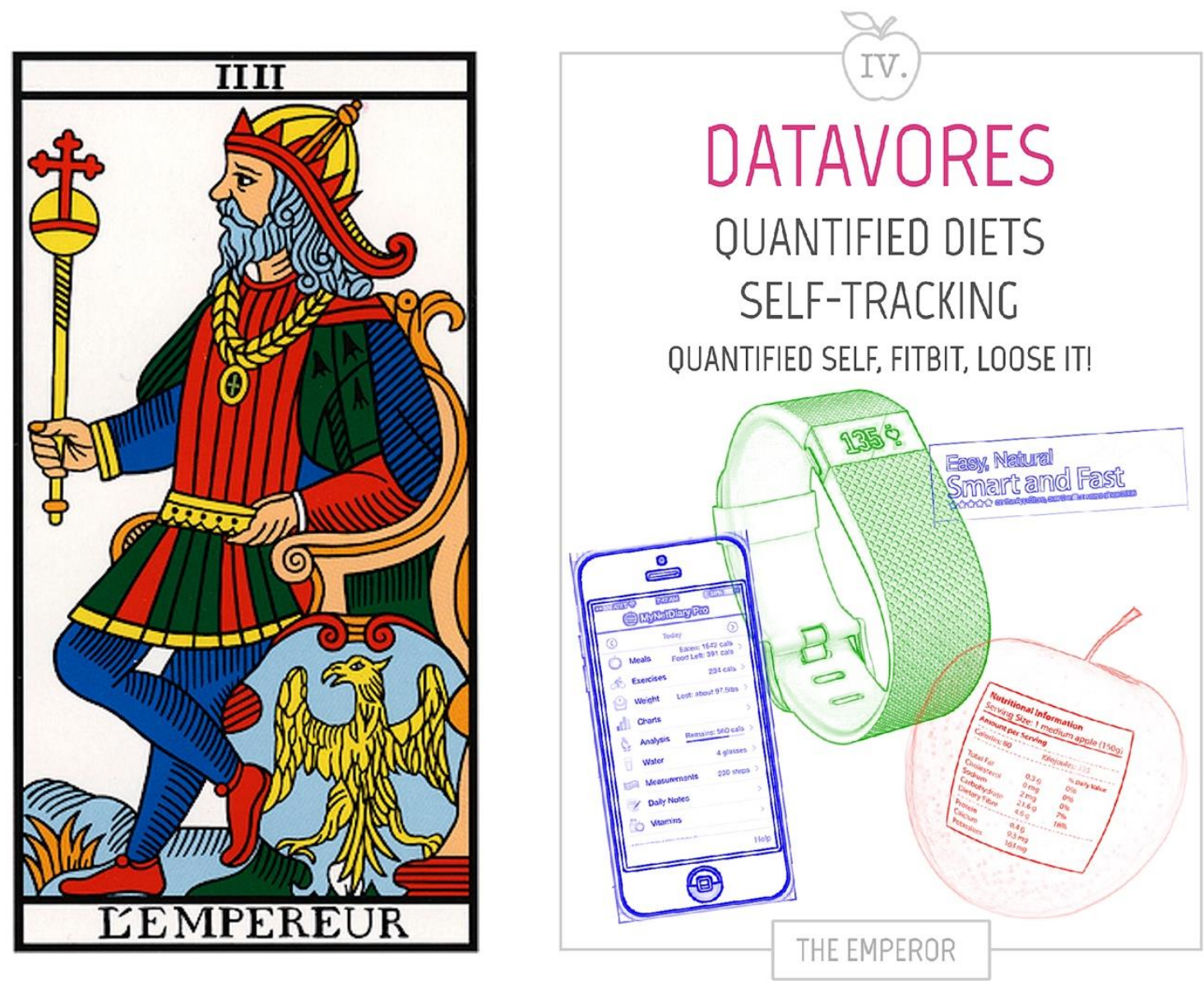

Figure 2: Datavores and The Emperor. 


\section{Parlour Events and Participants}

The Parlour of Food Futures was initiated in 2017 in Phoenix, Arizona (USA) as part of a larger project called Parlour of Futures (http://futureparlor.tumblr.com/). The initial Parlour was created for the annual Emerge: A Festival of Futures by a group of designers, philosophers, technologists and Tarot readers. Since the first Emerge event, the Food Parlour has been performed as a standalone project by the author of this text and various guest collaborators. Here, we focus on five selected Parlour events organised between 2017-19 at the following occasions: the initial Emerge festival in Phoenix (25. - 26. 02. 2017); the Maker Faire Singapore (22. - 23. 07. 2017); the VVitchVVaVVe festival in Melbourne, Australia (8. 12. 2018); the Biotopia EAT festival in Munich, Germany (26. 05. 2019); and the Cross Festival in Prague, Czech Republic (26. 07. 2019). All hosting festivals were free of charge and open to the public. At all five occasions, the Parlour oracle was attended by participants of various ages, professional backgrounds and personal interests. The number of participants ranged from 53 at the crowded Maker Faire to one single participant who sat down for a 2-hour long Food Tarot session at the sparsely populated Cross festival.

Following our aim to engage a casual audience of lay food practitioners, we did not set any specific requirements on participants' skills and expertise. Although there were no criteria for participant selection, we paid careful attention to choosing an appropriate venue for each of the Parlour events. Each of the five hosting festivals was thematically relevant to the scope and focus of the Parlour project: Biotopia EAT was explicitly focused on emerging food trends; Maker Faire revolved around emerging tech innovations, including innovations in the food-tech sector. The main theme of the Emerge festival was "Frankenstein" and biotechnological futures, where food-tech plays an important part. Finally, the VVitchVVaVVe and the Cross Festival looked into the possible futures of humanity, while focusing on techno-shamanistic practices and post-digital aesthetics. The Parlour was a good fit there as well.

\section{Event Activities}

At each event, Parlour activities involved participants in one-on-one Food Tarot card readings, followed by crafting of food futures scenarios. The readings were largely similar to card readings performed in a traditional Tarot parlour: visitors (participants) sat down, shuffled the deck and picked a card, and the reading began. The reader then initiated a conversation about the selected card and the possible future that it represents, asking questions about participants' experiences, ideas and opinions. Based on the responses, the reader kept selecting 2-4 additional cards from the deck that were either aligning or contrasting to what had been said. Eventually, we thus ended up with a larger card collage —or a prophecy_representing a possible food future co-created together with the participant. The reading conversations usually took between 10-30 minutes, depending on the participant's willingness to engage. 
When the reading was finished, each participant was asked to select one card from the final mix that felt "the most important" and craft a short what-if scenario imagining that she or he is a member of the selected food-tech tribe. We wanted to support the notion of food-tech issues as personal affairs and frame the idea of possible food futures as personal food futures that should concern each one of us. The scenarios could have multiple forms, including a written text, a drawing, or a crafted artefact (we provided basic tools such as sheets of coloured paper, pens and color pencils, post-its, duct tape, glue and scissors).

During the five events, we collected notes from 145 Food Tarot readings, and the same number of scenarios. We took hand-written notes rather than recording the dialogues-this less obtrusive method of note-taking proved to be more suitable for the public and casual context of the events. The notes and scenarios were analysed manually, using an inductive, qualitative analysis approach (Miles et al., 1994). Parlour events were always introduced as research events. Participants were able to provide oral informed consent, ask further questions about the project and withdraw from the interaction at any time.

\section{Participant Interactions \& Reflections}

During the card readings, participants often shared salient observations from the social context of their local foodscapes. At the Emerge festival in Phoenix, many participants mentioned local food security issues and the frequent presence of food deserts (i.e., areas with limited access to affordable and nutritious food). In response to the Gastro Masochists card-referring to dieters deliberately restricting their food consumption with the help of calorie trackers and smart utensils-one participant mentioned that such "masochism" is often involuntary for people living in the Phoenix food deserts. He pointed out the global food security paradox, where wealthy consumers often need to avoid "an overload of ubiquitous food options and dietary information". Less privileged people, on the contrary, suffer from hunger-both for food and food knowledge. This remark directed our reading dialogue towards the issue of unequal socio-economic access to food technologies: food-tech products are often accessible only to consumers with purchasing power and, hence, extend the socio-economic inequalities that already constrain food systems (more on such inequalities can be found in Norton et al., 2017). Provoked by the SD card, our reading conversation unfolded into a critical reflection on existing food system problems.

At the Maker Faire, a local food sustainability advocate opened a discussion on Singaporean food policy issues. Reacting to the Urban Foragers card-a food tribe making and using online crowdsourced maps of free-growing edible plants, as a form of sustainable food practice-she highlighted that although Singapore suffers from substantial food sustainability problems, local authorities restrict foraging in a majority of public (i.e., state-owned) areas. She also mentioned that although foraging is in the "grey zone" there, other sustainable food practices are available to citizens, such as app-assisted food sharing. We thus added two additional cards on the Tarot table, the P2P Farmers and the Food Altruists-tribes using online forums and apps to share their surplus produce and leftover food. In her future scenario, the participant proposed a speculative "Compost in a Pocket (CiP)": a wearable device to help users overcome the local foraging restrictions. Using the Pocket and a connected smartphone app, CiP volunteers would 
walk around the city and collect people's food waste. The Pocket would process this legally "foraged" food waste into compost for the volunteers to deliver to local small-scale farms that can use it as a fertiliser (figure 3). Her scenario presented an optimistic vision of a food future where technology extends, rather than replaces, existing food practices and is designed with a consideration of the specific local social conditions.

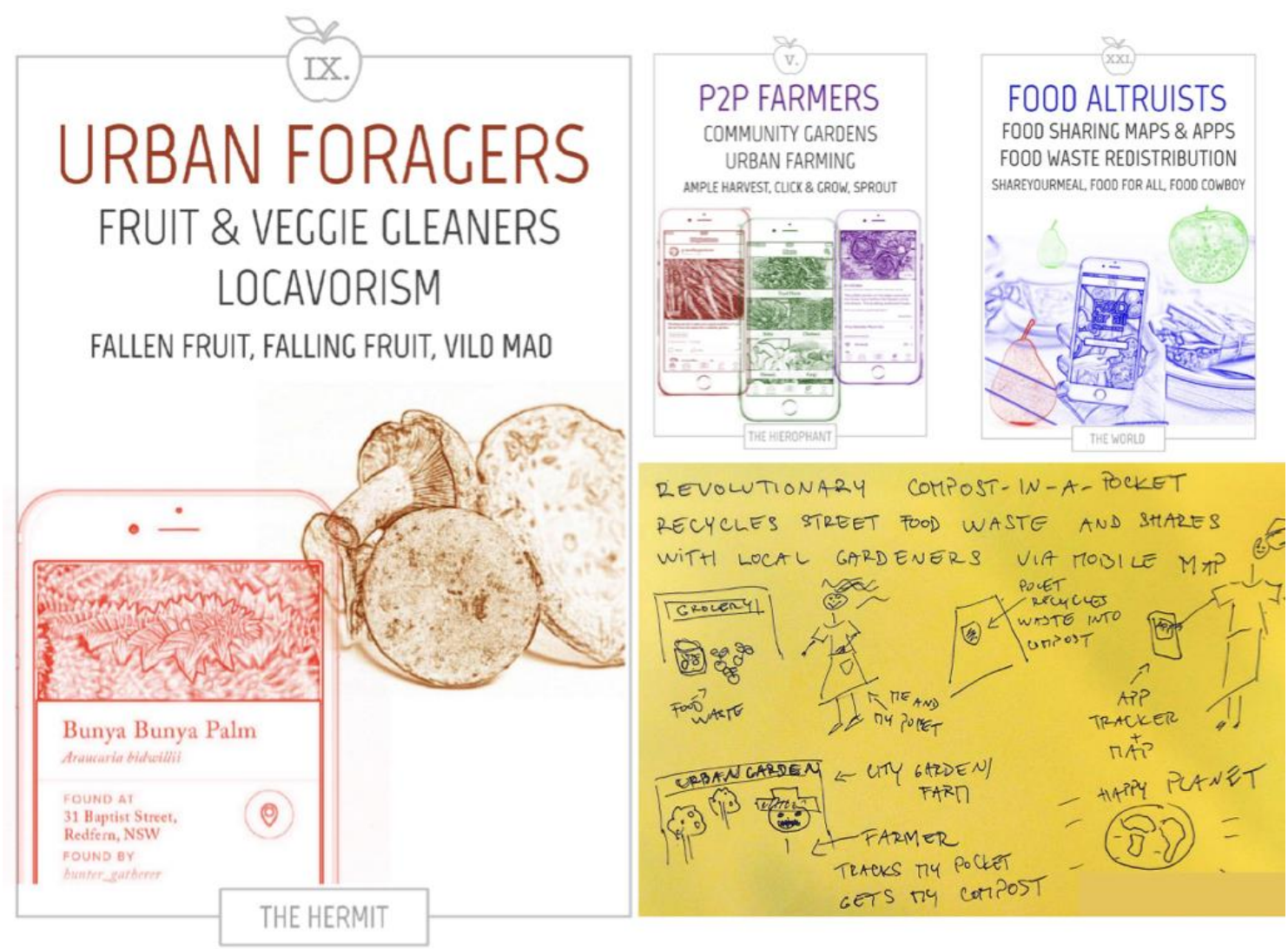

Figure 3: Compost in a Pocket scenario.

However, this optimism was not frequent during the Tarot readings, and many scenarios involved skeptical or even dystopian views of food futures. Reflecting on the Genomic Fatalists card, a participant at the Cross festival, highlighted that there is a growing volume of sensitive personal data that people share over online diet personalisation services. As a user of the FitBit tracker and the DNAFit genetic testing service herself, she mentioned that she feels somewhat uncomfortable sharing her biological data with commercial service providers. Her scenario included a drawing of herself walking on a street full of food shops-bakeries, ice cream parlours, cheese and wine boutiques-staring sadly into the shopping windows, unable to buy anything (figure 4). As she explained, her credit card (in the scenario world) is connected to her personal genetic data profile, which is managed by her health insurance company. Aiming to keep its clients fit and as profitable assets, the insurance company does not allow her to purchase unhealthy food or alcohol. This dystopian scenario illustrated participant's concerns with the potential role of novel food and diet personalisation technologies as surveillance tools restricting people's personal preferences and choices. 


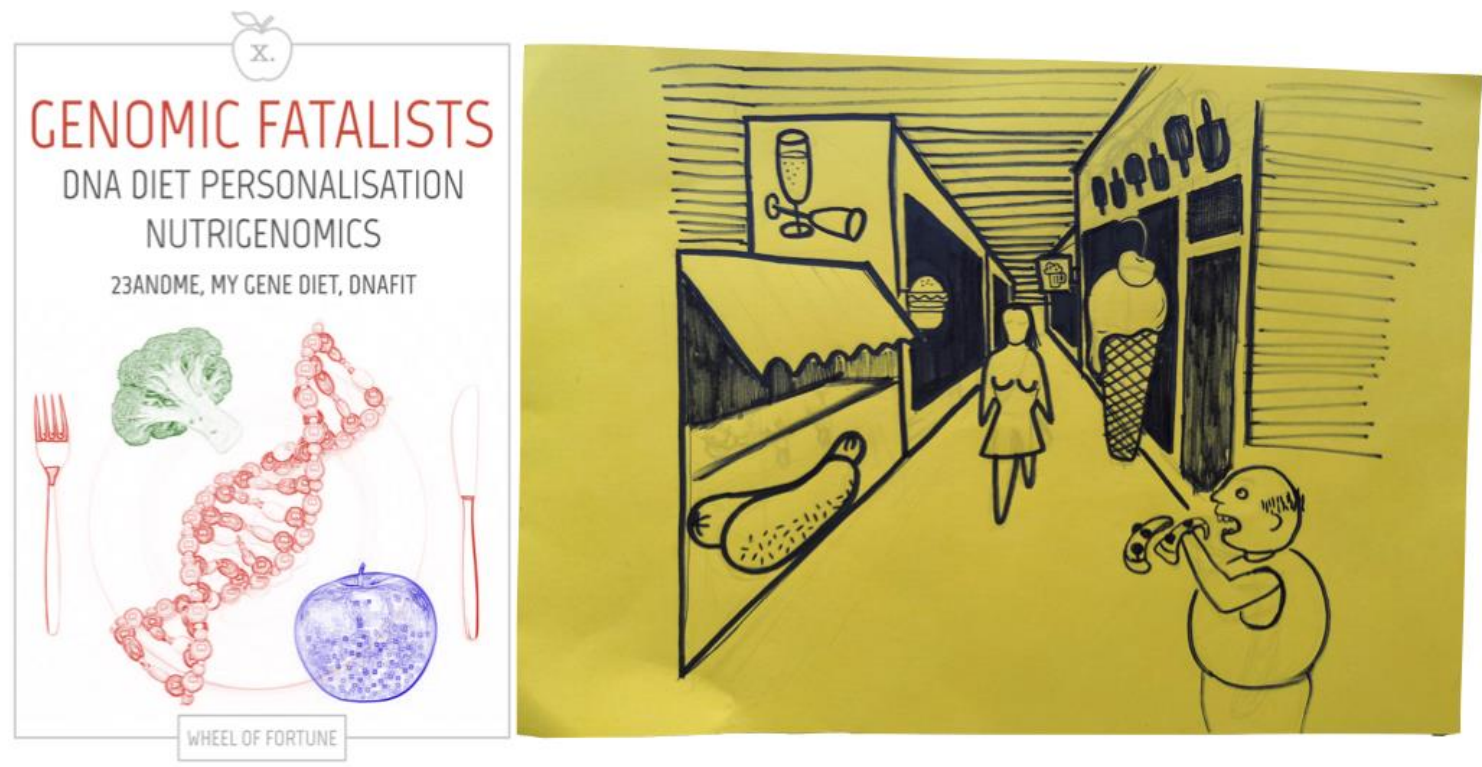

Figure 4: Genomic Fatalists and future food-tech surveillance.

The food ideas and envisionments shared in the Parlour were, to some extent, determined by the distinct thematic framing of the five hosting festivals. This can be demonstrated by the different ways in which participants reacted to the Food Gadgeteers card-a tribe using smart kitchenware such as Wi-fi enabled ovens or 3D food printers. At Emerge, a young mother of two kids highlighted the simulacral character of cooking with such smart food technologies: while having the illusion of preparing their food by themselves, users rely on algorithmic commands prescribed by smart machines. In her scenario, she envisioned a Food Gadgeteers future where people stop eating food altogether and become "Food Replicants". As she mentioned: "food practices will be effective but joyless. We will become a tasteless society of Food Replicants". At VVitchVVaVVe, the Food Gadgeteers card provoked an idea of rogue smart kitchenware that would use negative stimuli to change users' unhealthy food behaviour. For instance, a smart coffee machine that would release mild electric shocks to a user who wants to make more than one cup of coffee a day. These critical scenarios embodied participants' fears about a future where human-food relationships become fully automated and eaters get deprived of their control over food practices.

In contrast to this techno-scepticism, Parlour participants at Maker Faire-a festival celebrating technological innovation and tinkering - were often positive about human-food automation and highlighted the opportunities that novel food technologies afford to users. Many Maker Faire visitors had a personal experience with the latest smart food gadgets. One participant even thought that we are actually selling 3D food printers at the Parlour stall. This faux pas made us realise how important it is to maintain the "slight strangeness" of speculative designs (Dunne \& Raby, 2013) and tailor them carefully to specific local social contexts. The nuances of balancing 
slightly strange speculations were also felt around our Ethical Cannibals card-future dieters preferring to "eat themselves" as an ethical alternative to consuming animal protein. The card provoked both enthusiastic and puzzled reactions. For some participants, the idea of cannibalism as a positive ethical act was inspiring: a university student at Emerge imagined that, as a future Ethical Cannibal, he would consume specially modified probiotics to "hack" his gut flora to be able to grow edible mushrooms on his skin. Aside from feeding himself, he would offer this mushroom harvest to his friends and potential dates in a bar, which he named a Human-Food Exchange Club (figure 5). As he summarised: "rather than buying a depersonalised drink for my acquaintances, l'd offer my very own mushrooms".

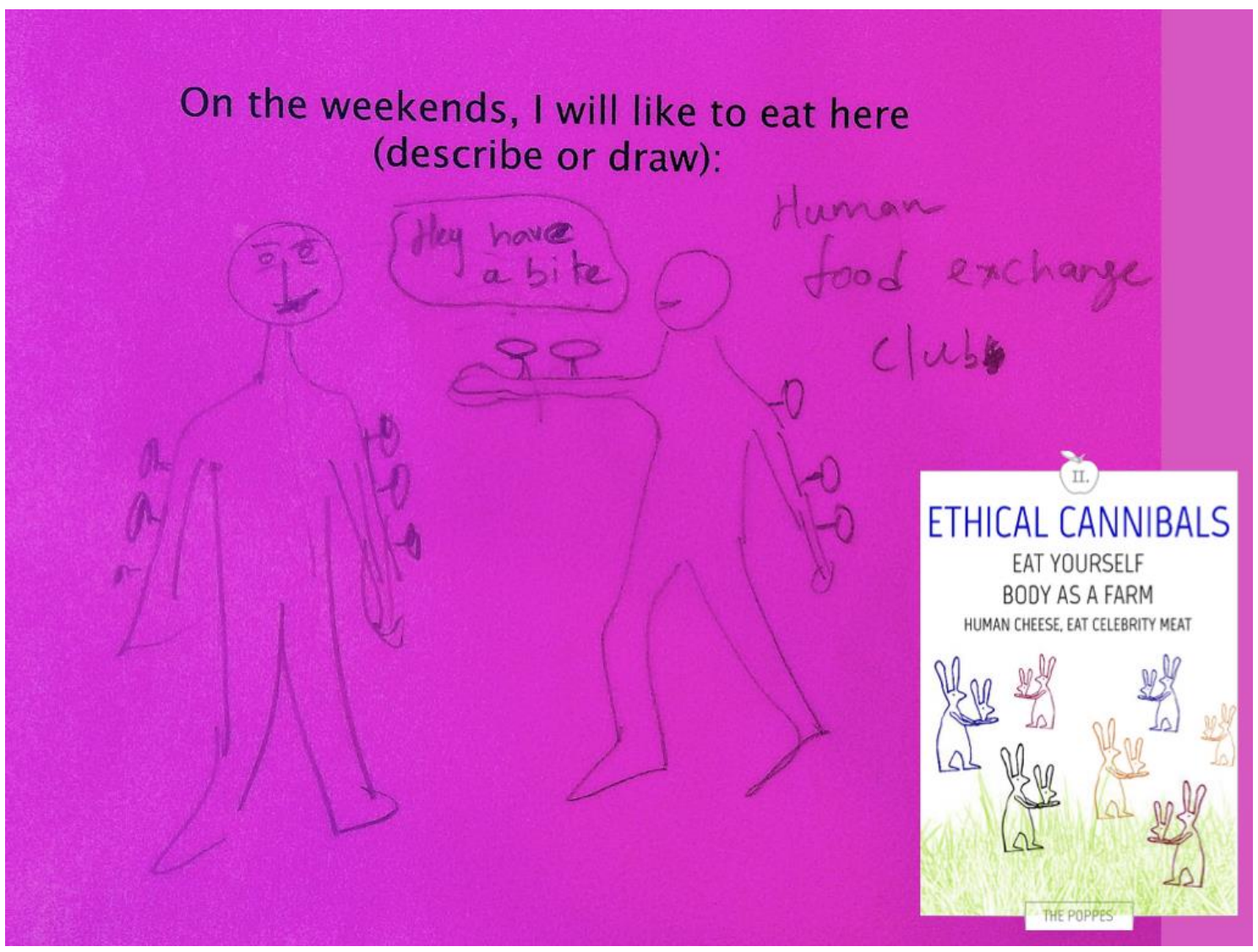

Figure 5: Ethical Cannibals and Human-Food Exchange Club scenario.

In his scenario, Ethical Cannibalism was not only a form of sustainable personalized nutrition but also a way to socialise with others. This speculation was not meant as a mere joke, but rather as a critical reflection of ethical issues related to the emerging trend of in-vitro meat grown in labs. One of the frequently discussed problems with lab-grown meat, as a supposedly cruel-free way of meat production, is that the trend foregrounds the idea that eating meat is not only fine, but also desirable and necessary. Critics suggest that promoting a plant-based diet is far more innovative than spending resources on costly in-vitro meat cultivation (see e.g., Schaefer \& Savulescu, 2014). In reflection, the Parlour participant explained that although his mushrooms would be grown on a human body and, hence, have the nutritional qualities of animal protein, the final product would look like a plant. Thereby, he would conveniently avoid 
promoting the idea of eating meat, and instead attract people's attention to plant-based nutrients. Similar imaginative response to Ethical Cannibals was presented at VVitchVVavve, by a participant who suggested the idea of "social breastfeeding". Instead of breastfeeding only her baby, the participant mentioned that she could imagine sharing the nourishing protein in her milk with a broader circle of her friends and family.

Unlike these two examples, many participants considered the Ethical Cannibals card as rather far-fetched and absurd, which limited their ability to relate to the idea and produce an interesting reflection. At the Biotopia festival, we collected several Ethical Cannibals scenarios that were overly simplistic: there were for instance the Broccoli Fingers-a scenario imagining growing broccoli seeds in the dirt behind one's fingernails, or the Herb Hairs, proposing to turn one's head into a herb garden (figure 6). While these scenarios were seemingly similar to the HumanFood Exchange Club, their authors did not provide any critical framing for their ideas: how, where and why would Broccoli Fingers and Herb Hairs work? For whom? No matter how cute or amusing these creations were, they did not help us to shed light on any of the food-tech issues related to the Ethical Cannibals card.
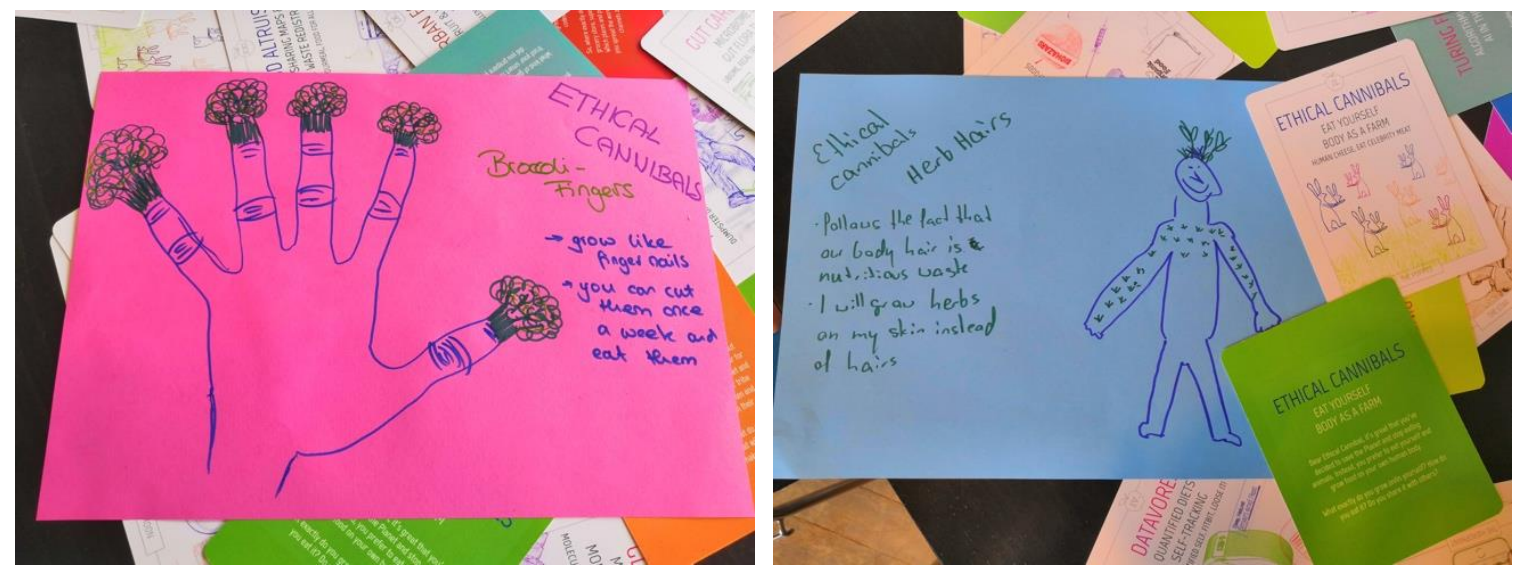

Figure 6: Broccoli Fingers and Herb Hairs scenarios.

At all five events, some participants kept fooling around rather than engaging in any reflective way. Their scenarios and reading contributions were often merely fun commentaries. One such scenario, crafted by a Maker Faire attendee, proposed that Nutri Explorers-a tribe exploring alternative nutrient sources such as insects and lab-grown food replacements-will "hate to eat insects with heavy poops". Why poops? Why heavy? What insects? The participant's cheeky response: "because everybody hates poops" was numbing. In cases like this, the Food Tarot deck functioned as a merely spectacular and fun tool rather than a speculative design tool prompting critical thinking. We will address these nuances, together with the other findings from the Parlour fieldwork, in the following discussion.

\section{DISCUSSION: EVENTFUL FOOD SPECULATIONS}

Our aim with the Edible Speculation project is to explore the opportunities and limitations of eventful SD as an approach to HFI research, and its potential in provoking people's creative, reflective engagements with food-technology issues. We outlined our findings from the Parlour 
of Food Futures case study that engaged diverse participants from the public in conversations about their food-tech experiences and concerns, followed by having them create imaginative proposals for possible food futures. These engagements were prompted by the Food Tarot deck, a SD artefact designed to provoke critical thinking about diverse social contexts of new food technologies. Such food contexts can be quite complex and challenging topics to engage with. The deck presents them in a playful way, to make the debate on food-tech practices and futures accessible for many people. During the Parlour events, issues related to food-tech innovation become a casual topic within reach of lay food practitioners. While certainly not accessible to all (not everyone has the option to visit festivals to engage in food design speculations), the Parlour engagements reached beyond the realm of professional designers, researchers and technologists.

The personal food-tech reflections shared by participants were both techno-optimistic and sceptical; provocative and practical; whimsical and serious. They touched upon broader social and political circumstances of food-tech innovation, as well as on specific local or personal contexts of food-tech practices. The breadth of these ideas illustrates a variety of perspectives on how to approach contemporary food-tech issues. Critically, the participation at Parlour events was motivated by the element of speculation - the provocative character of the Parlour oracle and the card deck artefact. Many participants mentioned that they would not be willing to contribute to more traditional food research formats, such as surveys and focus groups. The practice-led Parlour research project, along with its designerly approach to public engagement (Michael, 2012) centred around eventful SD, thus yielded an opportunity to glean insights from people who would likely not share them otherwise. Considering the everydayness of food and its diversity across social food contexts, such insights from diverse food practitioners can provide important contributions to research inquiries into food-tech issues and possible futures.

In the case of the Parlour, participants' contributions helped us to expand the ways in which we-as food design and research professionals - think about and reflect on the food-tech sector. The unfolding series of Parlour events enables us to collect food knowledge in various social settings and reflect in an iterative process of reflection-in-action (Schön, 1984): emerging insights are used to move forward with the research, but also to revisit previous considerations. In other words, each card reading and scenario session within the design research series generates some new insights into human-food-tech relationships that inform the events to come as well as our overall reporting of the Parlour project (c.f., Dolejšová, 2018a). Our first-hand perspective and involvement in-situ as researchers co-performing the speculation together with participants, is crucial in this regard. It is the direct creative engagement with participants and their responses to our initial speculative provocations (cards) that constitutes the Parlour as a knowledge-generating HFI project.

These engagements are meaningful not only for us from a design research perspective, but also for the participants themselves. Many people mentioned that they enjoyed staying in the Parlour: they were often keen on chatting with us and finding out more details about the project and upcoming events, as well as the possibility of getting a copy of the Food Tarot deck. Quite often we heard that the card readings revealed some new food-tech knowledge to participants 
and helped them understand how specific food-tech tools and practices work. One participant even mentioned that visiting the Parlour and engaging with the Food Tarot deck felt like being in an experimental "live food Wikipedia". Such feedback suggests that the events provided a playful occasion for mutual knowledge exchange and learning. That the at-the-moment Parlour experiences were in some way rewarding for the participants is vital, as they are the main form of remuneration for participants' contributions to the project.

However, it is important to note that not all interactions in the Parlour were meaningful from the design research point of view. On several occasions, participants stayed preoccupied with the whimsical character of the cards and unable to provide any reflective feedback. The Broccoli Fingers, Herb Hairs, and Insect Poop scenarios provide illustrative examples. This failure to elicit a meaningful response from participants may have been due to a variety of reasons. Besides a host of personal factors, such as participants' momentary mood or the limited time they had available for the interaction, the Food Tarot cards might have felt too far-fetched or perhaps too whimsical to some people, making the proposed speculations unrelatable to them. This is not an unusual problem in SD projects that need to carefully balance the "slight strangeness" of their provocations. Failing to keep this balance might result in what Francisco Laranjo (2015) calls "criticool" speculative designs that function as a mere spectacle rather than prompts for critical thinking. In exhibitable SD, this is often determined by aesthetic aspects of a SD artifact and its immediate appeal to the spectators. SD events at which designers interact with participants in-situ provide a better possibility to assist participants in their engagements with an artifact and help clarify its intended purpose. While this option to shepherd the interactions and steer them towards a meaningful exchange is an advantage of eventful SD, designers need to be careful with how and how much they intervene. During the Parlour readings, we wanted to keep our presence as neutral as possible and avoid being didactic, or influencing participants with our own food-tech interpretations. A challenge for us, and for other SD authors as well, is to keep our design provocations relatable and comprehensible without being too explanatory and suggestive.

The Parlour events performed in uncurated public settings present an especially challenging case in this regard, since it is virtually impossible for us to know who will show up at the Food Tarot table. People of any age, with various levels of food/design/technology experience can sit down for a reading, which creates an opportunity for collecting very diverse and potentially interesting insights as well as the risk of encountering misunderstanding and ending up facilitating un-critical food drawing sessions. We do not have any good way to solve this: stopping participants from drawing broccoli fingers and asking them to please be more reflective does not make any sense. Even seemingly silly scenarios, such as the Human-Food Exchange Club, can end up being meaningful and inspiring food-tech reflections. In the spontaneous, everyday Parlour setting, any response is potentially interesting: our job is to ask good follow-up questions about the scenarios content and help participants articulate a compelling future food narrative. When the answers are simplistic, such as in the poop case, and participants do not wish to go more in depth with their future envisionments, then we are left with just that.

This may be seen as a limitation of eventful speculations implemented in everyday public venues: the benefit of engaging diverse food perspectives and enabling spontaneous 
participation comes with some uncertainty and unpredictability attached. While acknowledging this limitation, we consider this a worthwhile trade-off and we value the food insights generated through the spontaneous Parlour engagements. Besides the five public events discussed here, we have used our Food Tarot deck in more curated contexts of workshops at academic $\mathrm{HFI} / \mathrm{HCl}$ conferences (e.g., FoodCHI'17, CHI'18, OzCHI'18, DIS'19, DIS'20). These venues provided a more formal setting, where selectively enrolled participants with expected expertise in food-tech themes engaged in carefully structured design activities. The discussion and scenarios provoked by the cards were typically quite focused, and there was less space for confusion or disengagement as compared to the public Parlour events. Still, this does not mean that such workshop reflections were "better" than those elicited in the everyday and more unpredictable public contexts. In fact, some of the most inspiring responses that we have gathered so far come from the public Parlour sessions (the Human-Food Exchange Club scenario, for instance, inspired our short speculative fiction story published in a food studies journal: see Hey \& Dolejšová, 2018). To us, it thus seems that speculating in the everyday—naturally messy and contingent-world creates some risks but also opportunities to gain surprising and valuable insights into our design research themes. Collecting critical reflections in the everyday wilderness opens the opportunity to find out something new, unexpected and beyond our limited horizons as (food) design and research experts.

For now, Parlour of Food Futures remains an exploratory work that focuses on in-the-moment experiences in the oracle, without the ambition of facilitating long-term engagements and action. While this limited reach — caused largely by our limited time options-is not ideal, interested Parlour participants who get inspired by the cards can take it from there and follow on their own. After all, the card deck is available for anyone to use under a CC license. We do wish to acknowledge, however, that in light of current climate emergencies and public health crises, food practices urgently need to change and continuous long-term work supporting such changes is needed. Projects like the Parlour that help people reflect on food issues and imagine food futures are just a small, humble contribution to such efforts. A transformation of food systems, whether through technological innovation or other means, certainly requires more than a Food Tarot oracle. Still, if we cannot imagine how possible futures could look and what a positive change should entail, we have nothing to start with.

\section{CONCLUSION}

In this paper, we proposed that eventful SD can serve as a potent approach to critical HFI, enabling researchers to engage with diverse audiences and collect food insights. While drawing on our first-hand experience of design researchers as Tarot readers working with participants in the Parlour of Food Futures oracle, we outlined several opportunities and limitations of SD events in provoking critical food engagements in everyday settings. The Parlour events created a compelling opportunity for participants to engage in playful and imaginative, but also critical and reflective explorations of food-tech issues. Although the Parlour interactions were not flawless, the insights gathered through the card readings and scenarios helped us to expand our own understanding of diverse roles that technological innovation can play in food cultures. Other $\mathrm{HFI}$ and food researchers may find the eventful SD approach useful as well, and leverage 
it to learn more about diverse food-tech concerns and experiences. While our SD work focuses on food contexts, we suggest that the eventful approach to SD that is central to Edible Speculations can be used also elsewhere, in other areas where insights from diverse public stakeholders would have a value. We thus hope that our work will inspire not only food-oriented scholars but broadly any design researchers and practitioners interested in incorporating eventful SD approaches into their work.

\section{REFERENCES}

Baumann, K., Stokes, B., Bar, F. and Caldwell, B. (2017) 'Infrastructures of the Imagination: Community Design for Speculative Urban Technologies', Proceedings of the 8th International Conference on Communities and Technologies, Troyes, France, ACM. pp. 266-69.

Blythe, M., Andersen, K., Clarke, R., and Wright, P. (2016) 'Anti-Solutionist Strategies: Seriously Silly Design Fiction', Proceedings of the 2016 CHI Conference on Human Factors in Computing Systems, pp. 4968-4978.

Burton Nitta. (2011) Republic of Salivation, http://www.burtonnitta.co.uk/RepublicOfSalivation.html

CB Insights (2018, March 13). Hungry for Investment: Big Food Races Toward Startups, http://www.cbinsights.com/research/food-corporate-fund-startup-investment/

Center for Genomic Gastronomy. (2013) De-Extinction Deli, http://genomicgastronomy.com/work/2016-2/de-extinction-deli-to-go/

DiSalvo, C. (2012) 'Spectacles and Tropes: Speculative Design and Contemporary Food Cultures', The Fibreculture Journal, (20 2012: Networked Utopias and Speculative Futures).

DiSalvo, C. (2016) 'The Irony of Drones for Foraging: Exploring the Work of Speculative Interventions', Design Anthropological Futures: 139-152.

Dolejšová, M. (2018) 'Edible Speculations: Designing for Human-Food Interaction', PhD Thesis at National University of Singapore

Dolejšová, M. (2018a) 'Edible Speculations in the Parlour of Food Futures', Extended Abstracts of the 2018 CHI Conference on Human Factors in Computing Systems (CHI EA'18). ACM, New York, NY, USA, Paper alt13, 10 pages.

Dolejšová, M., Altarriba Bertran, F., Wilde, D. and Davis, H. (2019) 'Crafting and Tasting Issues in Everyday Human-Food Interactions', Companion Publication of the 2019 Designing Interactive Systems Conference 2019, ACM. pp. 361-64.

Dunne, A. and Raby, F. (2013) Speculative everything: design, fiction, and social dreaming: MIT Press.

Edible Futures (2019) https://thedifd.com/articles/an-exhibition-about-the-future-of-food/ 
Elsden, C., Chatting, D., Durrant, A. C., Garbett, A., Nissen, B., Vines, J. and Kirk, D. S. (2017), 'On Speculative Enactments', Proceedings of the $2017 \mathrm{CHI}$ Conference on Human Factors in Computing Systems, Denver, Colorado, USA, ACM. pp. 5386-99.

Future Food (2019) https://www.nemosciencemuseum.nl/en/activities-atnemo/exhibitions/future-food/

Future Food House (2013) https://marijevogelzang.nl/portfolio page/future-food-house/

Gaver, W. and Dunne, A. (1999) 'Projected realities: conceptual design for cultural effect', Proceedings of the SIGCHI conference on Human Factors in Computing Systems, ACM. pp. 600-07.

Hey, M. and Dolejšová, M. (2018) 'Speculative Fiction as Companion Species in Food Studies Research', The Graduate Journal of Food Studies, vol. 5, nr. 2.

Laranjo, F. (2015) Critical Everything, https://modesofcriticism.org/critical-everything/

Lupton, D. (2017) 'Cooking, eating, uploading: digital food cultures', The Bloomsbury Handbook of Food and Popular Culture, pp. 66-79.

Martins, L. P. d. O. (2014) 'Privilege and oppression: Towards a feminist speculative design', Design Research Society, DRS.

Meat the Future (2013) https://www.nextnature.net/projects/meat-the-future/

Michael, M. (2012) 'De-signing the object of sociology: Toward an 'idiotic'methodology', The Sociological Review, 60(1_suppl): 166-83.

Miles, M. B., Huberman, A. M., Huberman, M. A. and Huberman, M. (1994) Qualitative data analysis: An expanded sourcebook: Sage.

Morabito, G. (2018, August 6) Loathed Start-Up 'Bodega' Changes Name to 'Stockwell', https://www.eater.com/pop-culture/2018/8/6/17655590/bodega-start-up-name-change-stockwell

Norton, J., Raturi, A., Nardi, B., Prost, S., McDonald, S., Pargman, D., Bates, O., Normark, M., Tomlinson, B., Herbig, N. and Dombrowski, L. (2017) 'A grand challenge for $\mathrm{HCl}$ : food + sustainability', interactions, 24(6): 50-55.

Schaefer, G. O. and Savulescu, J. (2014) 'The ethics of producing in vitro meat', Journal of Applied Philosophy, 31(2): 188-202.

Schön, D. A. (1984) The reflective practitioner: How professionals think in action, Basic books.

Simun, M. and Songster, M. (2013) GhostFood, http://songster.net/projects/ghostfood/

Solberg, B. (2018) The ethics of Nutrigenomics, EFAD European Federation of the Associations of Dieteticians. 
Thackara, J. (2014) Republic of Salivation (Michael Burton and Michiko Nitta), Design and Violence, http://designandviolence.moma.org/republic-of-salivation-michael-burton-andmichiko$\underline{\text { nitta/ }}$

Tonkinwise, C. (2014) 'How We Intend to Future: Review of Anthony Dunne and Fiona Raby, Speculative Everything: Design, Fiction, and Social Dreaming', Design Philosophy Papers, 12(2): 169-87.

Wilde, D., Underwood, J., and Pohlner, R. (2014) 'PKI: crafting critical design', Proceedings of the 2014 conference on Designing interactive systems, ACM. pp. 365-74.

Willett, W., Rockström, J., Loken, B., Springmann, M., Lang, T., Vermeulen, S., Garnett, T., Tilman, D., DeClerck, F. and Wood, A. (2019) 'Food in the Anthropocene: the EAT-Lancet Commission on healthy diets from sustainable food systems', The Lancet, 393(10170): 447-92.

Wilson, M. (2016, November 15). This \$1,500 Toaster Oven Is Everything That's Wrong With Silicon Valley Design, https://www.fastcodesign.com/3065667/this-1500-toaster-oven-iseverything-thats-wrong-with-silicon-valley-design 